\title{
Non-specific urethritis A placebo-controlled trial of minocycline in conjunction with laboratory investigations
}

\author{
M. J. PRENTICE, D. TAYLOR-ROBINSON, AND G. W. CSONKA \\ From the Division of Communicable Diseases, Clinical Research Centre, Watford Road, Harrow, Middlesex, \\ and the Central Middlesex Hospital, Park Royal
}

\section{Summary}

The results of a double-blind therapeutic trial on 8I men suffering from non-specific urethritis (NSU) show that minocycline was more effective than a placebo. Before treatment Chlamydia trachomatis was isolated from 31 per cent. of the men, ureaplasmas from 58 per cent., and Mycoplasma hominis from 7.5 per cent. There is evidence that chlamydiae are a cause of urethritis. However, after minocycline therapy improvement in the clinical response of patients from whom only ureaplasmas were isolated was less significant, so that the evidence that these organisms are pathogenic is less convincing. Possible reasons for this are discussed, as are the implications of finding minocycline-resistant ureaplasmas in at least 6 per cent. of the patients who harboured these organisms. The symptoms and signs of patients from whom micro-organisms were not isolated also improved after minocycline therapy, implying that the aetiological agents in this group of patients are antibiotic-sensitive. However, the results do not exclude the possibility that a minocycline-resistant agent is the cause of urethritis in a minority of patients.

\section{Introduction}

The cause of non-specific urethritis (NSU) is, by definition, unknown, but suspected agents include the tetracycline-sensitive micro-organisms Chlamydia trachomatis and mycoplasmas. The latter organisms comprise Mycoplasma hominis and Tmycoplasmas, and because $\mathrm{T}$-mycoplasmas have the unique property of metabolizing urea those of human origin have recently been termed Ureaplasma urealyticum (Shepard, Lunceford, Ford, Purcell,

Received for publication October 17, 1975

Address for reprints: Dr. D. Taylor-Robinson, Clinical Research Centre, Watford Road, Harrow, HA1 3UJ
Taylor-Robinson, Razin, and Black, 1974). In addition, it is possible that other micro-organisms, such as corynebacteria, might cause some cases of NSU and, indeed, all these agents either individually or synergistically may be responsible for the disease.

The evidence that chlamydiae cause some cases of NSU has been strengthened recently by epidemiological and serological observations (Oriel, Reeve Powis, Miller, and Nicol, 1972; Holmes, Handsfield, Wang, Wentworth, Turck, Anderson, and Alexander, 1975) and by the results of the inoculation of primates (Darougar, Kinnison, and Jones, 1971a). However, the relationship of chlamydiae to selflimiting disease has not been established, nor have Koch's postulates been fulfilled for these or other micro-organisms in the urethra of man. M. hominis is generally not regarded as a cause of NSU (TaylorRobinson, Addey, Hare, and Dunlop, 1969) but the role of ureaplasmas is controversial and during the past 20 years at least twenty studies designed to investigate the part played by these organisms have been carried out (McCormack, Braun, Klein, and Kass, 1973; Taylor-Robinson, 1976). Some workers have isolated ureaplasmas with about equal frequency from men suffering from NSU and from control subjects without the disease, whereas others have isolated the organisms more frequently from men with disease. The factor which probably makes the greatest contribution to these differing results is the selection of controls. Because selection is difficult and because the results of these studies do not provide a firm conclusion about the role of ureaplasmas, it seems that investigations of a similar kind are not likely to be worthwhile. Although animal models may have a place in studying the role of ureaplasmas in NSU, inoculation of human volunteers would be of greater value. However, this may never be possible or on only a limited scale, and other lines of approach using human patients therefore need to be pursued. The effect of tetracycline on the isolation of both chlamydiae and ureaplasmas, and on symptoms and signs, might not only help to 
clarify the relationship between the micro-organisms and disease but also indicate whether an antibioticresistant, isolate-negative group of cases exists. If this were so, these are the patients in whom to seek further aetiological factors, whether viral, bacterial, physical, or immunological. In an attempt to elucidate these points, we have carried out a double-blind, placebo-controlled trial of minocycline in the treatment of NSU in conjunction with the isolation of chlamydiae and mycoplasmas.

\section{Patients and methods}

\section{Minocycline}

Minocycline (Minocin) is a long-acting tetracycline. Therapeutic blood levels of approximately $2 \mu \mathrm{g} . / \mathrm{ml}$. are maintained by 12-hrly oral administration (MacDonald, Kelly, Allen, Noble, and Kanegis, 1973) which reduces the problem of inadequate therapy in patients suffering from NSU. A loading dose of $200 \mathrm{mg}$. was followed by $100 \mathrm{mg}$. given 12-hrly for 6 days, a total dose of $1.3 \mathrm{~g}$.

\section{Patients}

Consecutive patients complaining of urethral discharge were examined. Specimens were taken with a bacteriological loop passed $2 \mathrm{~cm}$. into the urethra and smears were Gram-stained. If gonococci or yeasts were not seen and more than fifteen polymorphonuclear leucocytes were present in one microscopic field (magnification 800 to $1,000 \times$ ) the patient was admitted to the trial. Patients who had received antibiotics in the previous week, who had passed urine within the last $4 \mathrm{hrs}$, or who had been in recent contact with gonorrhoea or trichomoniasis were excluded.

\section{Experimental design}

The proposed trial was approved by an ethical committee. The patients were informed that the effect of a new form of tetracycline was being examined, that the prescribed course of tablets might not be effective, and that further treatment might be necessary the following week.

Tablets of minocycline and lactose placebo were packed identically and given to the patients so that neither they, the clinician, nor the microbiologist knew their nature. The patients were instructed to abstain from taking alcohol and from having sexual contact at least until the next visit a week later. Any patient who admitted to intercourse before that time was withdrawn from the trial. If, after treatment, a patient was not cured as indicated by the resolution of symptoms and the absence of leucocytes from a urethral smear, he was re-treated with a similar course of minocycline. The treatment code was not broken until all specimens had been tested microbiologically.

\section{Collection of specimens and procedure}

At the first visit, urethral specimens were taken to culture for gonococci, mycoplasmas, and chlamydiae. Patients were asked to return 7 days later, when they were questioned about symptoms and examined for discharge. If this was present, a Gram-stained smear was used to confirm the persistence of urethritis and a wet-film was examined for trichomonads. In the absence of discharge, it was not always possible to make a successful smear, although this was attempted. In all patients, specimens were taken again for culture of mycoplasmas and chlamydiae at this time If further treatment was necessary, a third set of specimens was taken after completion. At all visits the two-glass urine test was used to exclude an upper urinary tract infection as indicated by a clear second specimen. In some instances threads or haze in the first specimen were sought by naked eye to try to establish a possible relationship between them and the presence of micro-organisms in the urethra.

Isolation of micro-organisms

Specimens for the isolation of micro-organisms were taken in the following order.

Gonococci A swab or bacterial loop was used to inoculate urethral discharge on to chocolate agar, or more frequently 'GC selective agar medium' (Oxoid). These plates were transported to the laboratory in a candle extinction jar, incubated at $36^{\circ} \mathrm{C}$. in 2 per cent. $\mathrm{CO}_{2}$ in air for $48 \mathrm{hrs}$ and examined for the presence of Gram-negative, oxidase-positive diplococci.

Mycoplasmas A swab passed $2 \mathrm{~cm}$. into the urethra was expressed into mycoplasma liquid medium which was stored at $-70^{\circ} \mathrm{C}$. These specimens were later titrated in urea-containing medium for the detection of ureaplasmas and in arginine-containing media for $M$. hominis (Taylor-Robinson, Williams, and Haig, 1968), the identity of the latter being confirmed by the use of specific antiserum in the disc growth-inhibition test.

Chlamydiae A specimen, taken with an abrasive plastic sponge-tipped swab, passed $2 \mathrm{~cm}$. into the urethra, was expressed into sucrose-phosphate transport medium and stored in liquid nitrogen until inoculated into McCoy cell cultures (Darougar, Kinnison, and Jones, 1971b). In some cases, instead of $\gamma$-irradiation, the cell monolayers were treated with $30 \mu \mathrm{g} . / \mathrm{ml}$. of 5 -iodo- $2^{\prime}$-deoxyuridine for 3 days before inoculation.

Antibiotic sensitivity tests

The sensitivity of ureaplasmas to minocycline and erythromycin was tested by a micro-technique (TaylorRobinson, 1967) in which each well in the micro-plate contained about $10^{4}$ colour-changing units of ureaplasma. The dilution of antibiotic at which there was complete inhibition of colour change was recorded after incubation at $36^{\circ} \mathrm{C}$. for $18 \mathrm{hrs}$.

\section{Method of statistical analysis}

Fisher's exact probability test was used with one degree of freedom. Results were considered significant if $P<0.05$.

\section{Results}

\section{Clinical response to treatment}

Although 136 men suffering from NSU were seen initially, satisfactory paired specimens were obtained from only 81 of them (Table I). The interval between taking specimens was on average 8.5 days (range 7 to 21). Minocycline was given to 46 patients, and at their second visit $41(89.2$ per cent.) were free from symptoms and signs but five ( 10.8 per cent.) still had a discharge. Placebo was given to 35 patients, 
TABLE I Effect of minocycline and placebo on disease

\begin{tabular}{|c|c|c|}
\hline \multirow{3}{*}{$\begin{array}{l}81 \mathrm{NSU} \\
\text { patients }\end{array}$} & Treatment & Clinical response \\
\hline & $\begin{array}{l}\text { MINOCYCLINE } \\
46 \text { patients }\end{array}$ & $\left\{\begin{array}{l}41(89.2 \text { per cent. }) \text { symptom and } \\
\text { sign free } \\
5(10.8 \text { per cent. }) \text { persistent } \\
\text { discharge }\end{array}\right.$ \\
\hline & $\begin{array}{l}\text { PLACEBO } \\
35 \text { patients }\end{array}$ & $\left\{\begin{array}{l}10(28.5 \text { per cent. }) \text { symptom and } \\
\text { sign free } \\
25(71.5 \text { per cent. }) \text { persistent } \\
\text { discharge }\end{array}\right.$ \\
\hline
\end{tabular}

and at their second attendance ten ( 28.5 per cent.) were free from symptoms and signs and $25(71.5$ per cent) had a discharge.

Micro-organisms initially isolated

Of the 81 patients studied in the trial (Table II) chlamydiae were isolated from 25 (31 per cent.), ureaplasmas from 47 (58 per cent.), and $M$. hominis from six (7.5 per cent.). Both chlamydiae and ureaplasmas were isolated from nine (11 per cent.) and none of these organisms was found in eighteen. These results are similar to those of the tests on the 136 patients who were seen only once.

TABLE II Organisms initially isolated from NSU patients

\begin{tabular}{|c|c|c|}
\hline Isolation & $\begin{array}{l}81 \text { patients in trial } \\
(\text { No. and per cent. positive })\end{array}$ & $\begin{array}{l}136 \text { NSU patients } \\
\text { (per cent.) }\end{array}$ \\
\hline $\begin{array}{l}\text { Chlamydia alone } \\
\text { Chlamydia } \\
\text { ureaplasma } \\
\text { Ureaplasma alone } \\
\text { Ureaplasma and } \\
\text { M. hominis }\end{array}$ & $\left.\begin{array}{rl}16(19 \cdot 7) & \left.\begin{array}{l}\text { Total chlamydia } \\
9(11 \cdot 1)\end{array}\right\} \begin{array}{l}25(31) \\
32(39 \cdot 5)\end{array} \\
6(7.5)\end{array}\right\} \begin{array}{l}\text { Total urea- } \\
\text { plasma } 47(58)\end{array}$ & $31 \cdot 6$ \\
\hline Isolate negative & $18(22 \cdot 2)$ & $25 \cdot 5$ \\
\hline Total & $81(100)$ & \\
\hline
\end{tabular}

Response of initially chlamydia-positive patients to treatment

Clinical response As shown in Table IIIA, the disappearance of symptoms and signs was significantly correlated with minocycline therapy, but not with administration of placebo (Fisher's exact test; $P<0.002)$. Ureaplasmas were also isolated from nine of the 25 chlamydia-positive patients and, as shown in Table IIIB, the correlation mentioned above still exists in a significant manner (Fisher's exact test $P=0.007)$ if the patients from whom only chlamydiae were isolated are considered.

Microbiological response Chlamydiae were isolated after treatment from only one of twelve initially chlamydiapositive patients who were given minocycline, whereas the organisms were recovered from nine of thirteen placebo-treated patients (Table IV). This relationship between the isolation of organisms and treatment is significant $(P<0.005)$, and it is still seen

TABLE IV Results of treating all initially chlamydia-positive patients

\begin{tabular}{|c|c|c|c|c|}
\hline \multirow{2}{*}{\multicolumn{2}{|c|}{ Culture result after treatment }} & \multicolumn{2}{|c|}{ Treatment } & \multirow{3}{*}{$\begin{array}{l}\begin{array}{l}\text { Total } \\
\text { patients }\end{array} \\
9\end{array}$} \\
\hline & & Placebo & Minocycline & \\
\hline \multirow{3}{*}{$\begin{array}{l}\text { Chlamydia } \\
\text { POSITIVE }\end{array}$} & $\begin{array}{l}\text { Persistent } \\
\text { discharge }\end{array}$ & 8 & 1 & \\
\hline & $\begin{array}{l}\text { Symptom and } \\
\text { sign free }\end{array}$ & 1 & 0 & 1 \\
\hline & Total & 9 & 1 & 10 \\
\hline \multirow{3}{*}{$\begin{array}{l}\text { Chlamydia } \\
\text { NEGATIVE }\end{array}$} & $\begin{array}{l}\text { Persistent } \\
\text { discharge }\end{array}$ & 3 & 0 & 3 \\
\hline & $\begin{array}{l}\text { Symptom and } \\
\text { sign free }\end{array}$ & 1 & 11 & 12 \\
\hline & Total & 4 & 11 & 15 \\
\hline
\end{tabular}

TABLE II Clinical response to treatment of initially Chlamydia and ureaplasma culture-positive patients

\begin{tabular}{|c|c|c|c|c|c|}
\hline \multirow{2}{*}{ Treatment } & \multirow{2}{*}{$\begin{array}{l}\text { No. of } \\
\text { patients }\end{array}$} & \multicolumn{2}{|c|}{ Symptom and sign free } & \multicolumn{2}{|c|}{ Persistent discharge } \\
\hline & & No. & Per cent. & No. & Per cent. \\
\hline $\begin{array}{l}\text { A. TOTAL chlamydia positive } \\
\text { Minocycline } \\
\text { Placebo }\end{array}$ & $\begin{array}{l}12 \\
13\end{array}$ & $\begin{array}{r}11 \\
2\end{array}$ & $\begin{array}{l}91 \cdot 6 \\
15 \cdot 6\end{array}$ & $\begin{array}{r}1 \\
11\end{array}$ & $\begin{array}{l}8 \cdot 4 \\
84 \cdot 4 \\
P<0.002\end{array}$ \\
\hline $\begin{array}{l}\text { B. ONLY chlamydia positive } \\
\text { Minocycline } \\
\text { Placebo }\end{array}$ & $\begin{array}{l}8 \\
8\end{array}$ & $\begin{array}{l}8 \\
2\end{array}$ & $\begin{array}{l}100 \\
25\end{array}$ & $\begin{array}{l}0 \\
6\end{array}$ & $\begin{array}{l}75 \\
P=0.007\end{array}$ \\
\hline $\begin{array}{l}\text { C. TOTAL ureaplasma positive } \\
\text { Minocycline } \\
\text { Placebo }\end{array}$ & $\begin{array}{l}24 \\
23\end{array}$ & $\begin{array}{r}20 \\
6\end{array}$ & $\begin{array}{l}83 \cdot 3 \\
26 \cdot 0\end{array}$ & $\begin{array}{r}4 \\
17\end{array}$ & $\begin{array}{l}16 \cdot 7 \\
74 \cdot 0 \\
P=0.0002\end{array}$ \\
\hline $\begin{array}{l}\text { D. ONLY ureaplasma positive } \\
\text { Minocycline } \\
\text { Placebo }\end{array}$ & $\begin{array}{l}17 \\
15\end{array}$ & $\begin{array}{r}14 \\
6\end{array}$ & $\begin{array}{l}82 \cdot 2 \\
40 \cdot 0\end{array}$ & $\begin{array}{l}3 \\
9\end{array}$ & $\begin{array}{l}17 \cdot 8 \\
60 \cdot 0 \\
P \leqslant 0.034\end{array}$ \\
\hline
\end{tabular}


$(\mathbf{P}=0.007)$ if we consider patients from whom only chlamydiae were isolated (Table V).

TABLE V Results of treating patients from whom only chlamydiae were isolated

\begin{tabular}{|c|c|c|c|c|}
\hline \multirow{2}{*}{\multicolumn{2}{|c|}{ Culture result after treatment }} & \multicolumn{2}{|c|}{ Treatment } & \multirow{2}{*}{$\begin{array}{l}\text { Total } \\
\text { patients }\end{array}$} \\
\hline & & Placebo & Minocycline & \\
\hline \multirow{3}{*}{$\begin{array}{l}\text { Chlamydia } \\
\text { POSITIVE }\end{array}$} & $\int \begin{array}{c}\text { Persistent } \\
\text { discharge }\end{array}$ & 5 & 0 & 5 \\
\hline & $\begin{array}{c}\text { Symptom and } \\
\text { sign free }\end{array}$ & 1 & 0 & 1 \\
\hline & Total & 6 & 0 & 6 \\
\hline \multirow{3}{*}{$\begin{array}{l}\text { Chlamydia } \\
\text { NEGATIVE }\end{array}$} & $\int \begin{array}{l}\text { Persistent } \\
\text { discharge }\end{array}$ & 1 & 0 & 1 \\
\hline & $\begin{array}{c}\text { Symptom and } \\
\text { sign free }\end{array}$ & 1 & 8 & 9 \\
\hline & Total & 2 & 8 & 10 \\
\hline
\end{tabular}

After treatment, there was a significant correlation $(P<0.005)$ between the presence or absence of symptoms and signs and the persistence of or failure to isolate chlamydiae in 21 of 25 initially chlamydia-positive patients (Table IV). Similarly, in the group of patients from whom only chlamydiae were isolated (Table $\mathrm{V}$ ), the association was still observed $(P<0.02)$.

\section{Response of initially ureaplasma-fositive patients to treatment}

Clinical response As shown in Table IIIC, the disappearance of symptoms and signs was significantly correlated with minocycline therapy, but not with the administration of placebo $(P=0.0002)$. Chlamydiae were also isolated from nine of the 47 ureaplasma-positive patients, but if the patients from whom only ureaplasmas were isolated are considered (Table IIID) the improvement in clinical response after minocycline treatment is far less significant $(P \leqslant 0.034)$. This result differs from that observed for chlamydiae.

TABLE VI Results of treating all initially ureaplasma-positive patients

\begin{tabular}{|c|c|c|c|c|}
\hline \multirow{2}{*}{\multicolumn{2}{|c|}{ Culture result after treatment }} & \multicolumn{2}{|c|}{ Treatment } & \multirow{3}{*}{$\begin{array}{l}\begin{array}{l}\text { Total } \\
\text { patients }\end{array} \\
18\end{array}$} \\
\hline & & \multirow{3}{*}{$\begin{array}{c}\text { Placebo } \\
16 \\
3\end{array}$} & \multirow{2}{*}{$\frac{\text { Minocycline }}{2}$} & \\
\hline \multirow{3}{*}{$\begin{array}{l}\text { Ureaplasma } \\
\text { POSITIVE }\end{array}$} & $\begin{array}{l}\text { Persistent } \\
\text { discharge }\end{array}$ & & & \\
\hline & $\begin{array}{l}\text { Symptom and } \\
\text { sign free }\end{array}$ & & 3 & 6 \\
\hline & Total & 19 & 5 & 24 \\
\hline \multirow{3}{*}{$\begin{array}{l}\text { Ureaplasma } \\
\text { NEGATIVE }\end{array}$} & $\begin{array}{l}\text { Persistent } \\
\text { discharge }\end{array}$ & 1 & 2 & 3 \\
\hline & $\begin{array}{l}\text { Symptom and } \\
\text { sign free }\end{array}$ & 3 & 17 & 20 \\
\hline & Total & 4 & 19 & 23 \\
\hline
\end{tabular}

Microbiological response Ureaplasmas were isolated from five of 24 initially ureaplasma-positive patients who were given minocycline treatment, whereas the organisms were recovered from nineteen of 23 placebo-treated patients (Table VI). This relationship between the isolation of organisms and treatment is significant $(P<0.0002)$, and the relationship is still apparent $(P=0.004)$ if we consider patients from whom only ureaplasmas were isolated (Table VII).

TABLE VII Results of treating patients from whom only ureaplasmas were isolated initially

\begin{tabular}{|c|c|c|c|c|}
\hline \multirow{2}{*}{\multicolumn{2}{|c|}{ Culture result after treatment }} & \multicolumn{2}{|c|}{ Treatment } & \multirow{3}{*}{$\begin{array}{l}\begin{array}{l}\text { Total } \\
\text { patients }\end{array} \\
9\end{array}$} \\
\hline & & \multirow{2}{*}{$\frac{\text { Placebo }}{8}$} & \multirow{2}{*}{$\frac{\text { Minocycline }}{1}$} & \\
\hline \multirow{3}{*}{$\begin{array}{l}\text { Ureaplasma } \\
\text { POSITIVE }\end{array}$} & $\left(\begin{array}{c}\text { Persistent } \\
\text { discharge }\end{array}\right.$ & & & \\
\hline & $\begin{array}{l}\text { Symptom and } \\
\text { sign free }\end{array}$ & 3 & 2 & 5 \\
\hline & Total & 11 & 3 & 14 \\
\hline \multirow{3}{*}{$\begin{array}{l}\text { Ureaplasma } \\
\text { NEGATIVE }\end{array}$} & $\begin{array}{c}\text { Persistent } \\
\text { discharge }\end{array}$ & 1 & 2 & 3 \\
\hline & $\begin{array}{l}\text { Symptom and } \\
\text { sign free }\end{array}$ & 3 & 12 & 15 \\
\hline & Total & 4 & 14 & 18 \\
\hline
\end{tabular}

After treatment, there was a significant correlation $(P<0.0002)$ between the presence or absence of symptoms and signs and the presence of or failure to isolate ureaplasmas in 38 of 47 initially ureaplasmapositive patients (Table VI), and this association persists $(P<0.02)$ in the group of patients from whom only ureaplasmas were isolated (Table VII).

Response of initially isolate-negative patients to treatment

Four of eighteen isolate-negative patients were given placebo and fourteen were treated with minocycline (Table VIII). Only one patient in each group had symptoms and discharge at the second attendance, and all but one were still isolate-negative. The exception was the placebo-treated patient with symptoms and discharge from whom ureaplasmas

TABLE VIII Results of treating eighteen $(22 \cdot 2$ per cent) initially isolate-negative patients

\begin{tabular}{|c|c|c|c|}
\hline Treatment & $\begin{array}{l}\text { No. of } \\
\text { patients }\end{array}$ & Symptoms & $\begin{array}{l}\text { Isolation after } \\
\text { treatment }\end{array}$ \\
\hline MINOCYCLINE & 14 & $\begin{array}{l}\text { Persistent } \\
\text { discharge } \\
\text { Symptom and } \\
\text { sign free }\end{array}$ & 13 All negative \\
\hline PLACEBO & 4 & $\begin{array}{l}\text { Persistent } \\
\text { discharge } \\
\text { Symptom and } \\
\text { sign free }\end{array}$ & $\begin{array}{l}1 \text { Ureaplasma isolated } \\
3 \text { Negative }\end{array}$ \\
\hline
\end{tabular}


were cultured. Unfortunately, the small size of the placebo group prevents statistical analysis of these results.

\section{Relationship of some aspects of clinical history to the results of treatment}

(i) Race The patients consisted of 61 Caucasians and twenty who were not Caucasian, of whom thirteen were West Indians. The symptomatic or microbiological response to either minocycline or placebo did not differ in the two racial groups.

(ii) Incubation period and duration of symptoms The interval between the most recent sexual intercourse or extramarital episode and the onset of symptoms was considered to be the minimum or probable incubation period of urethritis. No correlation was observed between the length of the incubation period and the micro-organisms which were initially isolated, either singly or in combination. Similarly, the duration of symptoms was apparently not related to the sort of micro-organism isolated.

\section{(iii) First and subsequent episodes of urethritis}

Clinical response Of the 81 patients in the trial, 39 claimed that this was their first episode, while the remainder had had one or more previous attacks. The clinical response to treatment was similar in these two groups of patients.

Microbiological response Chlamydiae were isolated from 33.4 per cent. of patients during a first attack and from 28.5 per cent. of those with a history of NSU, a difference which is not significant. Ureaplasmas, however, were isolated more frequently from patients without (69 per cent.) than from those (48 per cent.) with such a past history $(P<0.05)$. It was also found that the number of patients from whom micro-organisms could not be isolated initially was significantly less $(P<0.05)$ among those having a first attack (12.8 per cent.) than among those who had had previous urethritis ( 31 per cent.).

\section{Relationship of signs to micro-organisms isolated}

(i) Two-glass urine test Urine samples from forty patients were examined in an attempt to discover whether abnormal signs in the urine correlated with the presence of symptoms and discharge and whether urinary signs or symptoms were associated with the isolation of a particular micro-organism. Haze or threads were seen significantly more frequently $(P<0.05)$ in the urine of patients with symptoms or discharge (69 per cent.) than in that of those without symptoms or discharge (21.5 per cent.). However, signs in the urine and the complaint of dysuria were not related to the presence or absence of either chlamydiae or ureaplasmas. (ii) Quantity of discharge The number of leucocytes seen on the Gram-stained smear was used as an indicator of the severity of disease. The numbers of leucocytes were subjectively graded into three categories, but were apparently not related to the presence or absence of micro-organisms in the discharge.

\section{Relationship of persistent micro-organisms to clinical outcome}

After treatment ureaplasmas were still isolated from the urethra of some men in whom there was no clinical indication for further antibiotics. In these patients, the observed disease-free interval between the end of treatment and either default or the return of urethritis was compared with that of ureaplasma negative men.

The mean period of freedom from symptoms and signs for all 81 patients was 6.3 weeks. Nine patients were not seen again after treatment and the longest observation period was 42 weeks. After minocycline treatment, ureaplasmas were isolated from six patients who were observed to be free from disease for an average of 5.8 weeks, a finding similar to the average 6.2 weeks observed in fifty ureaplasmanegative patients.

Placebo tablets were originally given to 34 patients. Since 21 of this group were re-treated with minocycline, only thirteen were observed after placebo alone. Four, who harboured ureaplasmas, were disease-free for an average of 8.5 weeks and eight who were apparently free of micro-organisms showed no signs of disease for an average of $4 \cdot 25$ weeks. There is, therefore, no evidence that the presence of ureaplasmas diminishes the observed disease-free interval. There was only one patient harbouring chlamydiae after treatment, and he was asymptomatic for a week before his urethritis returned.

\section{Antibiotic sensitivity of ureaplasmas isolated}

Ureaplasmas were re-isolated from five of 24 ureaplasma-positive minocycline-treated patients. The sensitivity of four of these strains was tested and three were found to be resistant, both before and after therapy, to 5-10 $\mathrm{\mu g} . / \mathrm{ml}$. minocycline. In contrast, all other ureaplasmas isolated were sensitive to $0.07 \mu \mathrm{g} . / \mathrm{ml}$. This means that the incidence of resistant ureaplasmas in all the ureaplasma-positive patients is at least 6 per cent. A similar pattern of resistance was seen in tests with tetracyline hydrochloride, but all isolates were sensitive to $0 \cdot 15$ $\mu \mathrm{g} . / \mathrm{ml}$. erythromycin.

\section{Discussion}

The association between minocycline treatment and the subsequent failure to isolate chlamydiae does not, 
of course, indicate that these organisms are pathogenic in the urethra. Nevertheless, the correlation between the presence of symptoms after treatment and the isolation of chlamydiae in the absence of mycoplasmas strongly suggests that chlamydiae are a cause of urethritis.

The initial chlamydial isolation rate of 31 per cent. in this study is lower than that obtained by some other workers. Our method of taking specimens, in contrast to the endourethral method of Dunlop, Vaughan-Jackson, and Darougar (1972), probably accounts for at least part of this difference. If we assume that 50 per cent. of the patients did, in fact, harbour chlamydiae, we should have found forty of 81 to be isolate-positive, that is fifteen more than we detected. Considering all the patients from whom we failed to isolate chlamydiae, the disappearance of their symptoms and signs is significantly related to minocycline treatment $(P<0 \cdot 001)$. If fifteen patients are removed from this 'chlamydia-negative' group, according to the distribution of results in Table IIIB (which shows the clinical response to treatment of patients from whom only chlamydiae were isolated), statistical analysis of the remainder still indicates that minocycline is clinically more effective than placebo $(P<0.002)$. This evidence suggests that minocycline-sensitive aetiological agent(s) other than chlamydiae exist. This calculation is based on the assumption that our chlamydial isolation procedure is inefficient. Although there are no reports of an isolation rate exceeding 50 per cent., it is possible that a much greater incidence of infection exists and extension of this reasoning would lead us to the conclusion that all cases of minocycline-responsive NSU are caused by chlamydiae. This cannot yet be proved and is no reason to neglect other possible aetiological agents.

In a preliminary report (Prentice, TaylorRobinson, and Csonka, 1976), we indicated that after treatment of NSU there was no strong statistical correlation between the presence of symptoms and signs and the isolation of ureaplasmas in the absence of the other micro-organisms. However, the present observations based on further information show that this relationship between symptoms and signs and isolation is as significant for ureaplasmas as for chlamydiae. There is, therefore, some evidence that ureaplasmas are pathogenic in the male urethra. However, although there is a significant association between minocycline therapy and the resolution of symptoms and signs in patients from whom ureaplasmas alone were isolated, it is less striking than in the case of chlamydiae. This situation could be accounted for either by the failure of patients to improve on minocycline therapy, or by improvement when given placebo. The latter seems most likely, since, in this study, symptoms and signs disappeared from 40 per cent. of these patients who were given placebo (Table IIID). The existence of some nonpathogenic ureaplasma strains among the isolates would explain these results. This concept of different degrees of pathogenicity among ureaplasma strains is in keeping with the observation that some bovine ureaplasma strains are pathogenic when inoculated experimentally into the udder whereas others are not (Gourlay, Howard, and Brownlie, 1972). If this situation did exist in man, the clinical response to antibiotic therapy would be somewhat unpredictable because of the unknown ratio of pathogenic to nonpathogenic strains.

Because ureaplasmas were re-isolated from five patients after minocycline therapy, we wondered whether the strains had developed resistance to minocycline as a result of this treatment or whether they were resistant before treatment. We tested the sensitivity of four of these isolates, and found that three were resistant to minocycline before treatment. In three of four patients, resistant ureaplasmas were associated with persistent urethritis. From one patient chlamydiae were also isolated after treatment. Since J. D. Treharne (personal communication) has found no tetracycline-resistant chlamydiae, despite repeated searching, it is possible that the patient failed to take the tablets as instructed. Since the resistant ureaplasmas are sensitive to erythromycin, as in the single case reported by Ford and Smith (1974), it would be valuable to observe the effect of treating with a combination of these antibiotics. The clinical response to elimination of ureaplasmas would further our understanding of the pathogenicity of these organisms. Other workers have also searched for ureaplasmas before and after treating patients with tetracyclines. Thus, Weström and Mårdh (1971) isolated ureaplasmas from women with symptoms and signs of infection of the genital tract. They found that the incidence one week after treatment with $600 \mathrm{mg}$. metacycline given daily was reduced only from 68 to 50 per cent., but offered no satisfactory explanation for the persistence of the organisms. On the other hand, Harrison, de Louvois, Blades, and Hurley (1975) could no longer isolate ureaplasmas from twenty of 21 infertile couples 2 weeks after they had treated them with $100 \mathrm{mg}$. doxycycline given daily. It is possible that these divergent results can be, at least partially, explained by the frequency with which strains are exposed to tetracycline in the particular population. It would seem that tetracyclineresistant mutants have a good opportunity of being selected in persons who attend a venereal disease clinic since such persons probably have repeated contact with the drug more frequently than others.

It is noteworthy that the symptoms and signs in isolate-negative patients tend to disappear after treatment with minocycline. This implies that the aetiological agents in this group of patients are antibiotic-sensitive and may be either the micro- 
organisms already considered or other bacteria. On the other hand, the disappearance of symptoms and signs may have been spontaneous and unrelated to minocycline therapy, and it is unfortunate that the number of patients in our placebo-treated, isolatenegative group is insufficient to resolve this point. As these interesting patients were in a minority, it would be helpful if there was a means of distinguishing them early in order to facilitate future studies of the aetiology of NSU. We therefore tried to find clinical features which were associated with the apparent absence of chlamydiae and mycoplasmas. However, the presumed incubation period, duration of symptoms, dysuria, number of leucocytes, and urine abnormalities were not useful distinguishing features of the isolate-negative group.

A significant majority of isolate-negative patients had had a previous episode of urethritis. It is possible that micro-organisms were present in the urethra, but were prevented from growing in culture by the presence of an inhibitor, for example, antibody, stimulated as a result of an earlier encounter with the particular micro-organism. This hypothesis is supported by the finding that ureaplasmas were isolated significantly less frequently from those with a past history of disease than from those having a first attack. The equivalent data for chlamydial isolation were too few to be significant.

Microbiological follow-up studies of patients with urethritis in a normal community are of no value because it is very difficult to distinguish between relapse and re-infection when a recently treated patient suffers a recurrence of urethritis. To obtain reliable data it is necessary to examine a confined group of men, such as the crew of an aircraft carrier as studied by Holmes, Johnson, and Floyd (1967). Nevertheless, it is interesting to observe the subsequent clinical course of treated patients who are known to harbour possible pathogens. Our results showed that the disease-free interval was about the same whether or not ureaplasmas were being carried by the patients. This could be taken as further evidence for the non-pathogenicity of ureaplasmas. However, it is possible that some of these ureaplasmas are pathogenic but are not eliminated after resolution of disease.

Although we have presented good evidence that chlamydiae may cause NSU and have suggested that ureaplasmas are possibly involved in the aetiology, infection by many micro-organisms, irrespective of their sensitivity to minocycline, could theoretically result in a self-limiting disease.
If this were so, it would account for symptoms and signs in the 30 per cent. of all patients who apparently responded clinically to the placebo. Therefore, we cannot exclude the possibility that a virus or minocycline-resistant bacterium, either alone or by synergism, causes urethritis in a minority of patients.

We thank Dr. R. J. E. Daniel (Lederle Laboratories) for supplying the Minocin, and Mrs. Gillian Hutchinson, Dr. J. M. Behnke and Mr. R. T. Evans for their help in this study.

\section{References}

DAROUgaR, S., KINNISON, J. R., and Jones, B. R. (1971a) In 'Trachoma and Related Disorders', ed. R. L. Nichols, p. 501. Excerpta Medica, Amsterdam and New York

$\longrightarrow,-,-(1971 \mathrm{~b})$ Idem, p. 63

Dunlop, E. M. C., Vaughan-Jackson, J. D., and Darougar, S. (1972) Brit. F. vener. Dis., 48, 421

FORD, D. K., and SMITH, J. R. (1974) Ibid., 50, 373

Gourlay, R. N., Howard, C. J., and BrownlIE, J. (1972) F. Hyg. (Camb.), 70, 511

Harrison, R. F., DE Louvois, J., Blades, M., and HuRLEY, R. (1975) Lancet, 1, 605

Holmes, K. K., Handsfield, H. H., WANG, S. P., WeNTWORTH, B. B., TuRCK, M., ANDERSON, J. B., and Alexander, E. R. (1975) New Engl. F. Med., 292, 1199 - Johnson, D. W., and Floyd, T. M. (1967) F. Amer. med. Ass., 202, 474

MacDonald, H., Kelly, R. G., Allen, E. S., Noble, J. F., and KanEGIS, L. A. (1973) Clin. pharmacol. Ther., 14, 852

McCormack, W. M., Braun, P., LeE, Y.-H., Klein, J. O., and Kass, E. H. (1973) New Engl. F. Med., 288, 78

Oriel, J. D., Reeve, P., Powis, P., Miller, A., and Nicol, C. S. (1972) Brit. F. vener. Dis., 48, 429

Prentice, M. J., TAYlor-Robinson, D., and Csonka, G. W. (1976) In 'Chemotherapy'. Plenum Press, New York

Shepard, M. C., Lunceford, C. D., Ford, D. K., Purcell, R. H., TAylor-Robinson, D., RAzIN, S., and BLACK, F. T. (1974) Int. F. syst. Bact., 24, 160

Taylor-RobInson, D. (1967) Postgrad. med.f., Suppl. 43 (March), p. 100

- (1976) 'Scientific Foundations of Urology', vol. 1, p. 223. Heinemann, London

, Addey, J. P., Hare, M. J., and Dunlop, E. M. C. (1969) Brit. F. vener. Dis., 45, 265

- Williams, M. H., and HaIg, D. A. (1968) f. gen. Microbiol., 54, 33

WeströM, L., and MARDH, P.-A. (1971) Acta obstet. gynaec. scand., 50, 25 